\title{
Efek Tiga Jenis Pohon Penaung terhadap Keragaman Serangga pada Pertanaman Kopi di Perkebunan Rakyat Manglayang, Kecamatan Cilengkrang, Kabupaten Bandung
}

\author{
${ }^{1}$ Siska Rasiska, dan ${ }^{2}$ Abdirrassyiddin Khairullah \\ ${ }^{1}$ Departemen Hama dan Penyakit Tumbuhan, Fakultas Pertanian, Universitas Padjadjaran \\ Kampus Jatinangor, Jatinangor 45363 \\ ${ }^{2}$ Alumni Program Studi Agroteknologi, Fakultas Pertanian, Universitas Padjadjaran \\ *Alamat korespondensi: s.rasiska@unpad.ac.id
}

\begin{abstract}
The Effects of Three Types of Shade Trees on the Diversity of Insects in Coffee Plantation
\end{abstract}

\begin{abstract}
Arabican coffee (Coffea arabica) is one of the plantation commodities that has economic, social, and ecological value in Indonesia. Commonly, coffee is grown in a shaded condition that will affect the diversity of insects. This research was aimed to study the effects of three types of shade trees on the diversity of insects in coffee plants. This research was conducted at Manglayang Peasant Coffee Plantation, Cipulus Village, Cilengkrang Subdistrict, Bandung Regency and the Entomology Laboratory, Department of Plant Pests and Diseases, Faculty of Agriculture, Universitas Padjadjaran. The method used was descriptive survey through observation with systematic diagonal method in selected locations based on three types of shade trees, namely suren (Toona sureni Merr), white teak (Gmelina arborea Roxb), and pine (Pinus merkusii Jungh). The results showed that diversity index of the insects of coffee plants in suren shade trees was low to medium, and the highest percentage of abundance was Empoasca sp. Coffee plant diversity index of the insects with white teak shade trees were medium with highest percentage abundance in the Agromyzidae family and Emposca sp. Coffee plant diversity index of the insect with pine shading trees was low to moderate with the highest abundance of Empoasca sp. and Agromyzidae family.
\end{abstract}

Keywords: Shade tree, Diversity, Insect, Coffee plant

\begin{abstract}
ABSTRAK
Kopi arabika (Coffea arabica) merupakan salah satu komoditas perkebunan yang memiliki nilai ekonomi, sosial, dan ekologis bagi masyarakat Indonesia. Pada umumnya, kopi ditanam pada kondisi ternaungi sehingga akan berpengaruh terhadap keragaman serangga. Penelitian ini bertujuan untuk mengkaji efek dari tiga jenis pohon penaung terhadap keragaman serangga pada pertanaman kopi. Penelitian dilakukan di Perkebunan Kopi Rakyat Manglayang, Desa Cipulus, Kecamatan Cilengkrang, Kabupaten Bandung dan Laboratorium Entomologi, Departemen Hama dan Penyakit Tumbuhan, Fakultas Pertanian, Universitas Padjadjaran. Metode yang digunakan adalah survei deskriptif dengan cara observasi dengan metode diagonal sistematis pada beberapa lokasi yang dipilih berdasarkan tiga jenis pohon penaung, yaitu suren (Toona sureni Merr), jati putih (Gmelina arborea Roxb), dan pinus (Pinus merkusii Jungh). Hasil penelitian menunjukkan bahwa serangga tanaman kopi pada tanaman penaung suren indeks keragamannya rendah sampai sedang, dan persentase kelimpahan tertingginya adalah Empoasca sp. Serangga tanaman kopi dengan pohon penaung jati putih indeks keragamannya sedang dengan persentase kelimpahan tertinggi pada family Agromyzidae dan Emposca sp. Serangga tanaman kopi dengan pohon penaung pinus indeks keragamannya rendah hingga sedang dengan kelimpahan tertinggi Empoasca sp. dan famili Agromyzidae.
\end{abstract}

Kata Kunci: Pohon penaung, Keragaman, Serangga, Tanaman kopi 


\section{PENDAHULUAN}

Kopi merupakan salah satu komoditas perkebunan yang memiliki nilai ekonomi, sosial, dan ekologis bagi masyarakat Indonesia. Secara ekonomi, perkebunan kopi telah menghasilkan devisa yang cukup besar bagi negara melalui ekspor. Selain itu, perkebunan kopi juga telah menjadi sumber pendapatan bagi sebagian petani di pedesaan. Secara sosial, perkebunan kopi telah menyediakan lapangan pekerjaan dan mata pencaharian bagi penduduk di pedesaan. Secara ekologis, perkebunan kopi yang ditanam di area kehutanan telah menjadi area konservasi bagi tanah dan air serta memiliki keragaman hayati yang tinggi.

Berdasarkan pengelolaannya, perkebunan kopi di Indonesia dibagi ke dalam tiga kelompok besar, yaitu perkebunan kopi negara, perkebunan kopi swasta, dan perkebunan kopi rakyat. Berdasarkan luas lahannya, perkebunan kopi rakyat menempati urutan pertama sebesar $95,94 \%$ dari luas lahan kopi, dan sisanya dikelola oleh perkebunan kopi swasta dan negara. Selain itu, produktivitas tanaman kopi tertinggi juga dihasilkan dari perkebunan kopi rakyat. Menurut Badan Pusat Statistik Provinsi Jawa Barat (BPS, 2013), Bandung memiliki luas tanam untuk kopi terbesar di Jawa Barat, diikuti oleh Garut, Bogor dan Sumedang. Dari segi produksi, Bandung mendapat peringkat pertama tertinggi di Jawa barat, diikuti oleh Bogor, Garut dan Tasikmalaya. Dengan demikian, dapat dikatakan bahwa potensi perkebunan kopi rakyat di Jawa Barat, khususnya di Kabupaten Bandung dapat lebih ditingkatkan produktivitasnya, baik dari segi kuantitas maupun kualitas.

Secara ekologis pertanaman kopi memiliki keragaman serangga yang tinggi. Menurut Barrera (2008), terdapat sekitar 850 jenis serangga yang hidup di pertanaman kopi dan 23,5\% diantaranya menjadi hama di daerah tropis dan sub tropis. Semua bagian dari tanaman kopi dapat diserang dan dirusak oleh serangga sejak pembibitan hingga pertanaman. Akan tetapi, tidak semua serangga berperan sebagai hama yang bersifat merugikan bagi petani. Beberapa serangga yang berada di perkebunan kopi juga ada yang berperan sebagai polinator (penyerbuk) yang menguntungkan bagi tanaman kopi. Selain itu, serangga lainnya juga berperan sebagai pendegradasi bahan organik dan musuh alami bagi hama pemakan tanaman (fitophagous). Suatu studi di Mexico menunjukkan bahwa keberadaan organisme parasitoid dan predator di pertanaman kopi dapat mengendalikan atau mengatur populasi beberapa jenis hama.

Tanaman kopi merupakan tanaman perdu yang memerlukan naungan. Pohon naungan dapat memengaruhi keragaman serangga. Berdasarkan kajian, perkebunan kopi yang ternaungi memiliki keanekaragaman hayati yang sangat tinggi apabila dibandingkan dengan ekosistem hutan lainnya. Beberapa tanaman kehutanan yang berperan sebagai naungan bagi perkebunan kopi rakyat diantaranya adalah suren (Toona surenii), jati putih (Gmelina arborea Roxb.) dan pinus (Pinus merkusii Jungh \& De Vr). Akan tetapi, hingga saat ini belum diketahui keragaman serangga pada tanaman kopi ketiga jenis pohon naungan, yaitu suren, jati putih dan pinus. Dengan demikian, perlu dilakukan suatu kajian eksploratif mengenai keragaman serangga pada perkebunan kopi rakyat dengan tiga jenis pohon naungan. Penelitian ini dilakukan dengan tujuan untuk memelajari efek ketiga jenis pohon naungan terhadap keragaman serangga di perkebunan kopi rakyat.

\section{BAHAN DAN METODE}

Penelitian dilakukan di daerah Gunung Manglayang, Desa Cipulus, Kecamatan Cilengkrang, Kabupaten Bandung, dengan ketinggian lebih dari 1700 meter di atas permukaan laut. Penelitian ini menggunakan metode survey deskriptif. Tanaman kopi yang ijadikan sampel atau contoh adalah tanaman kopi yang telah berumur empat tahun dan telah berproduksi. Plot penelitian ditentukan berdasarkan pada kombinasi jenis tanaman kopi dengan tanaman penaungnya, yaitu suren, jati putih dan pinus.

Lahan berukuran $10 \mathrm{~m}$ x $10 \mathrm{~m}$ diambil secara acak pada lahan masing-masing kombinasi. Pada plot tersebut dibuat metode diagonal sistematis, sehingga dihasilkan lima titik pengamatan. Sampel serangga diambil dengan menggunakan aspirator, perangkap kuning (sticky yellow trap), dan perangkap fittfall. Jenis dan jumlah serangga yang terperangkap pada masing-masing jenis perangkap dihitung dan diidentifikasi. Identifikasi dilakukan dengan menggunakan buku Borror et al. (1989) dan Kalshoven (1981). Indeks keragaman dan kelimpahan serangga pada tanaman kopi dengan tiga jenis pohon pelindung dihitung berdasarkan Shannon-Wiener (Molles, 2008) sebagai berikut: 
$H^{\prime}=-\sum_{i=1}^{s} p i \log _{e} p i$

Keterangan:

H' = nilai dari indeks keragaman Shannon-Wiener

pi $=$ proporsi dari i spesies

$\log _{\mathrm{e}}=$ logaritma dari pi

$\mathrm{s} \quad=$ sejumlah spesies dalam komunitas

Nilai minimum dari $H^{\prime}$ adalah 0 , yang menunjukkan bahwa suatu komunitas hanya terdiri dari satu spesies. Nilai tersebut akan meningkat apabila kekayaan spesies dan kelimpahan relatif suatu spesies meningkat.

\section{HASIL DAN PEMBAHASAN}

\section{Keragaman Serangga pada Tanaman Kopi}

Berdasarkan hasil pengamatan, terdapat 8.077 ekor serangga yang tertangkap pada tanaman kopi dengan tiga jenis pohon naungan terdiri dari 12 ordo yang berperan sebagai herbivor (12 spesies), predator (11 spesies), parasitoid (2 spesies) dan saprovora (7 spesies) seperti disajikan pada Tabel 1. Hasil pengamatan menunjukkan spesies dari ordo Hemiptera memiliki jumlah yang dominan dibandingkan dengan spesies dari ordo lainnya. Hal ini dimungkinkan karena kondisi di pertanaman kopi dengan tiga jenis pohon pelindung tersebut merupakan habitat yang sesuai bagi perkembangan ordo Hemiptera, terutama Empoasca sp. Penelitian Rojas et al. (2001) juga menunjukkan tanaman kopi yang terlindungi akan didominasi oleh serangga hemiptera, Cicadellidae.

Tabel 1. Peran fungsional, identifikasi dan kelimpahan serangga di pertanaman kopi dengan tiga jenis pohon naungan.

\begin{tabular}{|c|c|c|c|c|}
\hline Peran fungsional & Ordo & Famili & Spesies & $\begin{array}{c}\text { Kelimpahan } \\
(\%)\end{array}$ \\
\hline \multirow{11}{*}{ Herbivora } & \multirow{4}{*}{ Coleoptera } & \multirow{4}{*}{ Scarabaeidae } & Apogonia sp. & 0,12 \\
\hline & & & Scarabaeidae a & 0,70 \\
\hline & & & Scarabaeidae $b$ & 0,05 \\
\hline & & & Scarabaeidae c & 0,14 \\
\hline & \multirow{4}{*}{ Diptera } & Agromyzidae & Agromyzidae & 6,16 \\
\hline & & \multirow{2}{*}{ Culicidae } & Culicidae a & 0,02 \\
\hline & & & Culicidae $b$ & 3,15 \\
\hline & & Tephritidae & Tephritidae & 1,88 \\
\hline & \multirow{3}{*}{ Hemiptera } & \multirow{2}{*}{ Cicadellidae } & Empoasca sp. a & 65,63 \\
\hline & & & Empoasca $s p . b$ & 3,54 \\
\hline & & Psyllideae & Heteropsylla sp. & 2,21 \\
\hline \multirow{2}{*}{ Parasitoid } & Diptera & Tachinidae & Zygobothria sp. & 0,70 \\
\hline & Lepidoptera & Autostichidae & Autostichidae & 0,07 \\
\hline \multirow{11}{*}{ Predator } & Acarina & Phytoseiidae & Phytoseiulus permilis & 0,05 \\
\hline & Araneae & Lycosidae & Lycosidae & 0,24 \\
\hline & Coleoptera & Coccinellidae & Adalia decempunctata & 0,46 \\
\hline & \multirow{2}{*}{ Dermaptera } & \multirow{2}{*}{ Forficulidae } & Forficulidae a & 0,12 \\
\hline & & & Forficulidae $b$ & 0,07 \\
\hline & Diptera & Dolichopodidae & Chrysosoma leucopogon & 6,90 \\
\hline & Hemiptera & Nabidae & Nabidae & 0,05 \\
\hline & \multirow{2}{*}{ Hymenoptera } & \multirow{2}{*}{ Formicidae } & Dolichoderus bituberculatus & 0,77 \\
\hline & & & Oecophylla smaragdina & 4,18 \\
\hline & Neuroptera & Chrysopidae & Chrysoperla rufilabris & 0,02 \\
\hline & Opiliones & Sclerosomatidae & Gagrella sp. & 0,43 \\
\hline \multirow{7}{*}{ Saprovora } & Blattodea & Termitidae & Termitidae & 0,19 \\
\hline & Coleoptera & Tenebrionidae & Asida sabulosa & 0,36 \\
\hline & Dermaptera & Anisolabididae & Anisolabididae & 0,26 \\
\hline & \multirow{3}{*}{ Diptera } & Cylindrotomidae & Cylindrotoma distinctissima & 0,10 \\
\hline & & Diopsidae & Diopsidae sp. & 0,02 \\
\hline & & Muscidae & Musca sp. & 0,58 \\
\hline & Orthoptera & Gryllidae & Gryllus campestris & 0,82 \\
\hline
\end{tabular}




\section{Kondisi Iklim Mikro pada Tanaman Kopi dengan Tiga Jenis Pohon Penaung}

Tiga jenis pohon penaung tanaman kopi, seperti suren, jati putih dan pinus akan memengaruhi pada kondisi iklim mikro. Suren merupakan tanaman industri yang dibudidayakan dengan tujuan untuk memperoleh kayunya. Suren berkanopi lebar dengan banyak daun dan harum. Suren sebagai pohon penaung tanaman kopi akan berpengaruh terhadap iklim mikro dan keragaman serangga. Berdasarkan pengamatan iklim mikro, suhu pada tanaman kopi dengan naungan suren berkisar antara $20,3^{\circ} \mathrm{C}$ hingga $23,0^{\circ} \mathrm{C}$, dengan suhu rata-rata mingguan adalah $21,85^{\circ} \mathrm{C}$. Kelembaban pada tanaman kopi dengan naungan suren berkisar antara $85 \%$ hingga $97 \%$, dengan kelembaban ratarata mingguan adalah $91,38 \%$. Intensitas cahaya matahari pada tanaman kopi dengan naungan suren berkisar antara 3295 lux hingga 13310 lux, dengan intensitas cahaya rata-rata mingguan adalah 8287,5 lux.

Suhu pada tanaman kopi dengan naungan jati putih berkisar antara $21,1^{\circ} \mathrm{C}$ hingga $23,8{ }^{\circ} \mathrm{C}$, dengan suhu rata-rata mingguan selama pengamatan adalah $22,39^{\circ} \mathrm{C}$. Kelembaban pada tanaman kopi dengan naungan jati putih berkisar antara $85 \%$ hingga 97\%, dengan kelembaban rata-rata mingguan selama pengamatan adalah 90,88\%. Intensitas cahaya matahari pada tanaman kopi dengan naungan jati putih berkisar antara 2417,5 lux hingga 6735 lux, dengan intensitas cahaya rata-rata mingguan selama pengamatan adalah 4620,4 lux. Kondisi iklim yang demikian akan memengaruhi keragaman dan kelimpahan serangga pada tanaman kopi dengan naungan jati putih.

Suhu pada tanaman kopi dengan naungan pinus berkisar antara $20,5^{\circ} \mathrm{C}$ hingga $25,3^{\circ} \mathrm{C}$, dengan suhu rata-rata mingguan selama pengamatan adalah $22,79^{\circ} \mathrm{C}$. Kelembaban pada tanaman kopi dengan naungan pinus berkisar antara 72\% hingga 99\%, dengan kelembaban rata-rata mingguan selama pengamatan adalah $87,63 \%$. Intensitas cahaya matahari pada tanaman kopi dengan naungan pinus berkisar antara 986,5 lux hingga 6430 lux, dengan intensitas cahaya rata-rata mingguan selama pengamatan adalah 4350,625 lux. Ketiga jenis pohon penaung tersebut juga akan memengaruhi pada keragaman serangga.

\section{Efek Pohon Penaung terhadap Keragaman Serangga}

Data pada Tabel 2 menunjukkan Indeks keragaman serangga pada tanaman kopi dengan pohon naungan suren termasuk pada kategori rendah hingga sedang. Indeks keragaman dengan kategori rendah menunjukkan keanekaragaman serangga yang rendah, produktivitas ekosistem yang rendah, kestabilan ekosistem yang rendah dan tekanan ekosistem yang berat. Indeks keragaman yang rendah pada tanaman kopi dengan pohon pelindung suren diduga karena suren mengandung senyawa kimia yang tidak disukai serangga dan dapat berperan sebagai repellent. Setiawati dkk. (2008) menyebutkan bahwa suren mengandung bahan kimia surenon, surenin dan surenolakton yang banyak terkandung di daun dan kulit kayu, yang dapat berfungsi sebagai penghambat pertumbuhan, penghambat makan, penolak (repellent) dan bahan insektisida nabati.

Berdasarkan waktu pengamatan, maka serangga pada tanaman kopi dengan pohon pelindung suren cenderung mengalami peningkatan keragaman, yaitu dari rendah ke sedang. Indeks keragaman dengan kategori sedang menunjukkan keanekaragaman serangga yang sedang, produktivitas ekosistem yang sedang, kestabilan ekosistem yang sedang pula. Kondisi yang berbeda terdapat pada indeks keragaman serangga pada tanaman kopi dengan pohon pelindung jati putih dan pinus yang termasuk pada kategori sedang. Kondisi ini menunjukkan habitat pada tanaman kopi dengan pohon pelindung jati putih dan pinus sesuai bagi sejumlah serangga. Pada tanaman kopi dengan pohon pelindung jati putih dan pinus cenderung mengalami penurunan. Peningkatan keragaman pada tanaman kopi dengan pohon pelindung suren menunjukkan seiring waktu habitat tersebut semakin sesuai untuk kehidupan serangga. Menurut Krebs (2001), terdapat faktor-faktor yang memengaruhi keberagaman serangga yaitu waktu, heterogenitas ruang, kompetisi, pemangsaan, kestabilan iklim dan produktivitas.

Berdasarkan pengamatan terhadap elemen iklim, maka suhu, kelembaban dan intensitas cahaya di tanaman kopi dengan pohon pelindung suren cenderung mengalami penurunan. Akan tetapi apabila dibandingkan dengan tanaman kopi dengan pohon pelindung jati putih dan pinus, maka elemen iklim di tanaman kopi dengan pohon pelindung suren cenderung suhunya lebih kecil (rata-rata $21,85^{\circ} \mathrm{C}$ ), kelembaban paling tinggi (rata-rata $91,38 \%$ ) dan intensitas cahaya paling besar (rata-rata 8287,5 lux). Kondisi ini ditunjang pula oleh anatomi atau morfologi tanaman suren yang berkanopi lebar, cabang rata dan memiliki banyak daun, sehingga memungkinkan sejumlah serangga untuk memilih habitat tersebut sebagai tempat hidup terutama 
serangga Empoasca sp. Berbeda dengan indeks keragaman serangga berdasarkan waktu pengamatan pada tanaman kopi dengan pohon pelindung jati putih dan pinus yang cenderung stabil dan sedikit berfluktuatif.

Tabel 2. Indeks keragaman serangga pada tanaman kopi dengan tiga jenis pohon penaung.

\begin{tabular}{cccccccccc}
\hline \multirow{2}{*}{ Waktu (MP) } & \multicolumn{3}{c}{ Mi } & \multicolumn{3}{c}{$\mathrm{H}^{\prime}$} & & \multicolumn{3}{c}{ Kategori } \\
\cline { 2 - 10 } & Suren & Jati putih & Pinus & Suren & Jati putih & Pinus & Suren & Jati putih & Pinus \\
\hline 1 & 1229 & 362 & 246 & 0,92 & 2,48 & 1,81 & Rendah & Sedang & Rendah \\
2 & 629 & 219 & 239 & 0,89 & 2,12 & 2,39 & Rendah & Sedang & Sedang \\
3 & 459 & 286 & 308 & 1,66 & 2,45 & 2,35 & Rendah & Sedang & Sedang \\
4 & 450 & 219 & 197 & 1,38 & 2,44 & 2,29 & Rendah & Sedang & Sedang \\
5 & 449 & 203 & 280 & 1,57 & 2,38 & 2,07 & Rendah & Sedang & Sedang \\
6 & 303 & 193 & 213 & 1,73 & 2,12 & 2,04 & Rendah & Sedang & Sedang \\
7 & 298 & 265 & 243 & 2,00 & 2,05 & 1,90 & Sedang & Sedang & Rendah \\
8 & 341 & 178 & 198 & 2,12 & 2,35 & 1,96 & Sedang & Sedang & Rendah \\
\hline
\end{tabular}

Kondisi ini juga terkait dengan elemen iklim berupa suhu, kelembaban dan intensitas cahaya. Suhu pada tanaman kopi dengan pohon pelindung jati putih dan pinus cenderung turun dengan rata-rata $22,39^{\circ} \mathrm{C}$ dan $22,79^{\circ} \mathrm{C}$. Kelembaban pada tanaman kopi dengan kedua pohon pelindung tersebut cenderung naik dengan rata-rata 90,88\% dan $87,63 \%$. Intensitas cahaya pada tanaman kopi dengan pohon pelindung jati putih cenderung naik dengan rata-rata 4620,4 lux, sedangkan kelembaban pada tanaman kopi dengan pohon pelindung pinus cenderung turun dengan rata-rata 4350,6 lux.

\section{SIMPULAN}

Jumlah total serangga yang tertangkap pada tanaman kopi dengan tiga pohon naungan yang berbeda sebanyak 8.077 ekor. Sejumlah serangga tersebut berasal dari 12 ordo. Dari sejumlah spesies serangga yang tertangkap, terdapat 12 spesies yang teridentifikasi sebagai serangga herbivor, 2 spesies sebagai serangga parasitoid, 11 spesies sebagai serangga predator, dan 7 spesies sebagai saprovora atau serangga netral pada tanaman kopi. Indeks keragaman serangga dengan pohon naungan suren termasuk pada kategori rendah hingga sedang, sedangkan dengan pohon naungan jati putih dan pinus termasuk pada kategori sedang. Indeks keragaman serangga berdasarkan waktu pengamatan menunjukkan serangga pada tanaman kopi dengan pohon pelindung suren cenderung mengalami peningkatan, sedangkan pada tanaman kopi dengan pohon pelindung jati putih dan pinus cenderung mengalami penurunan. Kelimpahan serangga hama herbivor yang tertinggi adalah spesies Empoasca sp. yang termasuk pada famili Cicadellidae dan ordo Hemiptera. Musuh alami yang kelimpahannya tertinggi adalah parasitoid Zygobothria sp. yang termasuk pada famili Tachinidae dan ordo Diptera serta predator Chrysosoma leucopogon yang termasuk pada famili Dolychopodidae dan ordo Diptera.

\section{DAFTAR PUSTAKA}

Badan Pusat Statistik. 2013. Jawa Barat dalam Angka. Luas Areal dan Produksi Tanaman Kopi Menurut Kepemilikan di Jawa Barat. Tersedia online pada http://jabar.bps.go.id. (diakses Desember 2014)

Barrera, JF. 2008. Coffee pest and their management. Pp 961-998 in Encyclopedia of Entomology. $2^{\text {nd }}$ Ed. (JL Capinera, Ed.). Springer, Dordrecht.

Borror, JD, CA Triplehorn, and NF Johnson. 1989. An Introduction to the Study of Insects. Saunders College Pub., Philadelphia.

Kalshoven, LGE. 1981. The Pests of Crops in Indonesia. Revised and translated by PA van der Laan and GHL Rothschild. PT. Ichtiar Baru-van Hoeve, Jakarta.

Molles, MC. 2008. Ecology: Concepts and Applications. $4^{\text {th }}$ Edition. McGraw-Hill International Edition,Boston.

Krebs, CJ. 2001. Ecology the Experimental Analysis of Distribution and Abundance. Benjamin Cummings, San Francisco. 
Rojas, L, C Godoy, P Hanson, and L Hilje. 2001. A survey of Homoptera Ssecies (Auchenorrhyncha) from Coffee Shrub and poro and laurel trees in shade coffee plantation, in Turriaalba Costa Rica. Rev.Biol.Trop. 49(3-4): 1057-1065.

Setiawati, W, R Murtiningsih, N Gunaeni, dan T Rubiati. 2008. Tumbuhan Bahan Pestisida
Nabati dan Cara Pembuatannya untuk Bahan Pengendalian Organisme Pengganggu Tanaman. Prima Tani Balitsa, Pusat Penelitian dan Pengembangan Hortikultura-Badan Penelitian dan Pengembangan Pertanian. Lembang. 